\title{
METODE NEWTON MIDPOINT HALLEY (NMH) UNTUK MENYELESAIKAN SISTEM PERSAMAAN NONLINIER
}

\author{
Fitri Nur Hidayah, Yundari, Mariatul Kiftiah
}

\begin{abstract}
INTISARI
Sistem persamaan nonlinier dapat diselesaikan dengan metode numerik salah satunya metode Newton. Metode Newton telah banyak dimodifikasi menjadi beberapa metode baru dengan tujuan dapat mereduksi jumlah iterasi dalam menyelesaikan sistem persamaan nonlinier. Pada penelitian ini dikombinasikan metode Newton, midpoint Newton dan Halley untuk menyelesaikan sistem persamaan nonlinier. Penyelesaian sistem persamaan nonlinier dengan kombinasi beberapa metode ini diawali dengan mencari solusi sistem persamaan nonlinier melalui metode Newton, kemudian nilai solusi tersebut disubstitusikan ke dalam metode Midpoint Newton. Selanjutnya nilai solusi dari metode Midpoint Newton disubstitusikan ke dalam metode Halley sebagai solusi akhir. Iterasi berhenti jika galat iterasi lebih kecil dari galat toleransi yang diberikan. Hasil numerik dari penelitian ini menunjukkan bahwa metode NMH dapat menyelesaikan sistem persamaan nonlinier.
\end{abstract}

Kata kunci: metode numerik, metode Halley, metode midpoint, metode Newton, NMH

\section{PENDAHULUAN}

Sistem persamaan nonlinier merupakan kumpulan dari beberapa persamaan nonlinier dengan fungsi tujuan dan atau dengan fungsi kendala berbentuk nonlinier [1]. Beberapa sistem persamaan nonlinier memerlukan metode numerik untuk mencari nilai akar persamaan. Metode numerik adalah teknik yang digunakan untuk memformulasikan masalah matematika sehingga dapat dipecahkan dengan operasi perhitungan biasa seperti tambah, kurang, kali, dan bagi [2]. Dalam metode numerik, pencarian akar $f(x)=0$ dilakukan secara iteratif sehingga menghasilkan nilai hampiran. Salah satu metode numerik yang digunakan untuk menyelesaikan sistem persamaan nonlinier adalah metode Newton. Beberapa tahun terakhir, metode Newton banyak dikombinasikan dengan metode lain dimaksudkan untuk mendapatkan metode baru yang lebih efisien. Metode Newton yang dikombinasikan dengan aturan Midpoint menghasilkan metode Midpoint Newton yang mampu memperoleh akar dari persamaan lebih cepat [3]. Kombinasi varian metode Newton yang dikombinasikan dengan metode Halley menghasilkan metode baru yang lebih cepat konvergen [4]. Pada penelitian ini mengkombinasikan metode Newton, Midpoint, dan Halley (NMH) yang kemudian diaplikasikan pada penyelesaian sistem persamaan nonlinier.

Langkah-langkah yang dilakukan dalam penelitian ini adalah diberikan suatu sistem persamaan nonlinier dengan titik awal $\mathbf{X}_{\mathbf{0}}$ dan nilai galat toleransi $\boldsymbol{E}_{\boldsymbol{\delta}}$ adalah $\mathbf{1 0}^{\mathbf{- 1 5}}$. Setelah itu lakukan iterasi pertama untuk mendapatkan $\mathbf{X}_{\mathbf{1}}$. Pada iterasi pertama, hitung dengan menggunakan metode Newton yang solusinya kemudian didefinisikan sebagai nilai $\mathbf{Z}_{\mathbf{0}}$, kemudian dilanjutkan metode Midpoint Newton yang solusinya kemudian didefinisikan sebagai nilai $\mathbf{Y}_{\mathbf{0}}$ dan yang terakhir dengan menggunakan nilai $\mathbf{Z}_{\mathbf{0}}$ dan nilai $\mathbf{Y}_{\mathbf{0}}$ pada metode Halley untuk mendapatkan nilai $\mathbf{X}_{\mathbf{1}}$. Berikutnya menentukan nilai galat iterasi pertama yaitu selisih mutlak nilai $\mathbf{X}_{\mathbf{1}}$ dan $\mathbf{X}_{\mathbf{0}}$ untuk mendapatkan norm galat pertama, ketika nilai norm galat pertama lebih kecil dari galat toleransi yang diberikan maka iterasi sudah selesai dan $\mathbf{X}_{\mathbf{1}}$ merupakan solusi dari sistem persamaan nonlinier. Tetapi ketika nilai norm galat pertama lebih besar atau sama dengan galat tolerasi yang diberikan, maka perlu dilakukan iterasi selanjutnya dengan $\mathbf{X}_{\mathbf{1}}$ sebagai tebakan awal sampai memperoleh solusi persamaan yang norm galatnya lebih kecil dari galat toleransi yang diberikan. 


\section{SISTEM PERSAMAAN NONLINIER}

Suatu persamaan dikatakan nonlinier jika suatu persamaan memiliki derajat variabel lebih atau kurang dari satu misalkan kuadrat, kubik, trigonometri atau dalam bentuk lainnya. Sistem persamaan nonlinier merupakan kumpulan dari beberapa persamaan nonlinier. Bentuk umum sistem persamaan nonlinier dapat ditulis sebagai berikut:

$$
\begin{gathered}
f_{1}\left(x_{1}, x_{2}, \ldots, x_{n}\right)=0 \\
f_{2}\left(x_{1}, x_{2}, \ldots, x_{n}\right)=0 \\
\vdots \\
f_{n}\left(x_{1}, x_{2}, \ldots, x_{n}\right)=0 .
\end{gathered}
$$

dengan fungsi $f_{i} ; i=1,2, \ldots, n$ merupakan fungsi yang memetakan dari $\mathbb{R}^{n}$ ke $\mathbb{R}$.

Sistem persamaan nonlinear juga dapat direpresentasikan dengan mendefinisikan fungsi $\mathbf{F}$ yang memetakan $\mathbb{R}^{n}$ ke $\mathbb{R}^{n}$ sebagai berikut:

$$
\mathbf{F}\left(x_{1}, x_{2}, \ldots, x_{n}\right)=\left(f_{1}\left(x_{1}, x_{2}, \ldots, x_{n}\right), f_{2}\left(x_{1}, x_{2}, \ldots, x_{n}\right) \ldots, f_{n}\left(x_{1}, x_{2}, \ldots, x_{n}\right)\right)^{T} .
$$

Jika variabel $\mathbf{X}=\left(x_{1}, x_{2}, \ldots, x_{n}\right)^{T}$ merupakan suatu vektor yang digunakan untuk menjelaskan sistem Persamaan (1) maka persamaan tersebut dapat ditulis dengan bentuk sebagai berikut:

$$
\mathbf{F}(\mathbf{X})=0 \text {. }
$$

\section{METODE NEWTON}

Metode numerik yang digunakan untuk mencari akar persamaan nonlinier salah satunya adalah metode Newton [1]. Penyelesaian persamaan nonlinier $f\left(x_{n}\right)$ menggunakan metode Newton memerlukan titik tebakan awal $x_{n}$ dan turunan pertama $f^{\prime}\left(x_{n}\right)$ disetiap iterasinya. Rumus iterasi metode Newton adalah

$$
x_{n+1}=x_{n}-\frac{f\left(x_{n}\right)}{f^{\prime}\left(x_{n}\right)} ; f^{\prime}\left(x_{n}\right) \neq 0, n=\mathbb{Z}^{+} .
$$

Rumus metode Newton untuk mencari akar suatu sistem persamaan nonlinier adalah

$$
\mathbf{X}_{\mathbf{n}+\mathbf{1}}=\mathbf{X}_{\mathbf{n}}-\mathbf{J}\left(\mathbf{X}_{\mathbf{n}}\right)^{-1} \cdot \mathbf{F}\left(\mathbf{X}_{\mathbf{n}}\right), n=\mathbb{Z}^{+}
$$

Persamaan (2) memerlukan tebakan awal $\mathbf{X}_{\mathbf{n}}$ dan matriks Jacobian $\mathbf{J}\left(\mathbf{X}_{\mathbf{n}}\right)$. Matriks Jacobian $\mathbf{J}\left(\mathbf{X}_{\mathbf{n}}\right)$ adalah turunan pertama fungsi $\mathbf{F}\left(\mathbf{X}_{\mathbf{n}}\right)$ yang dapat ditulis $\mathbf{F}^{\prime}\left(\mathbf{X}_{\mathbf{n}}\right)$. Matriks $\mathbf{J}\left(\mathbf{X}_{\mathbf{n}}\right)$ haruslah merupakan matriks nonsingular. Kriteria pemberhentian iterasi metode Newton adalah ketika norm galat iterasi lebih kecil dari pada galat toleransi atau dapat ditulis sebagai berikut

$$
\left\|\mathbf{E}_{\mathbf{n}+\mathbf{1}}\right\|<E_{\delta}
$$

$\operatorname{dimana} \mathbf{E}_{\mathbf{n}+\mathbf{1}}=\left|\mathbf{X}_{\mathbf{n}+\mathbf{1}}-\mathbf{X}_{\mathbf{n}}\right|$.

\section{METODE MIDPOINT}

Salah satu modifikasi metode Newton adalah metode Midpoint. Metode ini diusulkan oleh Ozban (2004) dengan mengaproksimasikan metode Newton, aturan midpoint dan aturan trapesium [4]. Rumus iterasi metode Midpoint adalah

$$
x_{n+1}=x_{n}-\frac{f\left(x_{n}\right)}{\frac{\left(f^{\prime}\left(x_{n}\right)+f^{\prime}\left(x_{n+1}\right)^{*}\right)}{2}}, n=\mathbb{Z}^{+},
$$

dimana $f^{\prime}\left(x_{n}\right)$ adalah turunan pertama dari persamaan yang diberikan $f\left(x_{n}\right)$ sedangkan $\left(x_{n+1}\right)^{*}$ dihitung dengan menggunakan metode Newton. Dalam pencarian akar suatu sistem persamaan nonlinier, metode Midpoint memerlukan tebakan awal $\mathbf{X}_{\mathbf{n}}$ dan titik tengah dari turunan pertama $\mathbf{F}\left(\mathbf{X}_{\mathbf{n}}\right)$ atau $\mathbf{J}\left(\mathbf{X}_{\mathbf{n}}\right)$ dengan $\mathbf{J}\left(\mathbf{X}_{\mathbf{n}+\mathbf{1}}^{*}\right)$ yang merupakan matriks jacobian dari iterasi $n+1$ menggunakan metode Newton. Rumus metode Midpoint untuk mencari akar suatu sistem nonlinier adalah,

$$
\mathbf{X}_{\mathbf{n}+\mathbf{1}}=\mathbf{X}_{\mathbf{n}}-\left(\mathbf{J}\left(\mathbf{X}_{\mathbf{n}}\right)+\mathbf{J}\left(\mathbf{X}_{\mathbf{n}+\mathbf{1}}^{*}\right)\right)^{-1} \cdot 2 \mathbf{F}\left(\mathbf{X}_{\mathbf{n}}\right), n=\mathbb{Z}^{+},
$$

dimana $\mathbf{X}_{\mathbf{n}+\mathbf{1}}^{*}=\mathbf{X}_{\mathbf{n}}-\mathbf{J}\left(\mathbf{X}_{\mathbf{n}}\right)^{-1} \cdot \mathbf{F}\left(\mathbf{X}_{\mathbf{n}}\right)$ dan matriks jacobian $\mathbf{J}\left(\mathbf{X}_{\mathbf{n}}\right)$ merupakan matriks nonsingular. Kriteria pemberhentian iterasi metode Midpoint adalah ketika galat iterasi lebih kecil dari pada galat toleransi yang diberikan atau dapat dilihat pada Persamaan (3). 


\section{METODE HALLEY}

Metode Halley merupakan metode perluasan dari metode Newton yang diperoleh dengan menggunakan deret Taylor yang dipotong hingga orde kedua. Rumus metode Halley untuk mencari akar suatu persamaan $f\left(x_{n}\right)$ dengan tebakan awal $x_{n}$ adalah

$$
x_{n+1}=x_{n}-\frac{2 f\left(x_{n}\right) f^{\prime}\left(x_{n}\right)}{\left(2 f^{\prime}\left(x_{n}\right)\right)^{2}-f\left(x_{n}\right) f^{\prime \prime}\left(x_{n}\right)}, n=\mathbb{Z}^{+},
$$

dimana $f^{\prime}\left(x_{n}\right)$ merupakan turunan pertama dari $f\left(x_{n}\right)$. Sedangkan rumus untuk mencari akar suatu sistem persamaan adalah,

$$
\mathbf{X}_{\mathbf{n}+\mathbf{1}}=\mathbf{X}_{\mathbf{n}}-\left(\mathbf{J}\left(\mathbf{X}_{\mathbf{n}}\right)-\frac{1}{2 !} \sum_{i=1}^{n} e_{i} \otimes\left\{\left(\mathbf{J}\left(\mathbf{X}_{\mathbf{n}}\right)^{-\mathbf{1}} \cdot \mathbf{F}\left(\mathbf{X}_{\mathbf{n}}\right)\right)^{\mathbf{T}} \mathbf{H}_{\mathbf{i}}\left(\mathbf{X}_{n}\right)\right\}\right)^{-1} \cdot \mathbf{F}\left(\mathbf{X}_{\mathbf{n}}\right), n=\mathbb{Z}^{+} .
$$

Dimana $\mathbf{J}\left(\mathbf{X}_{\mathbf{n}}\right)$ adalah matriks jacobian yang merupakan turunan pertama dari fungsi $\mathbf{F}\left(\mathbf{X}_{\mathbf{n}}\right), \mathbf{H}\left(\mathbf{X}_{\mathbf{n}}\right)$ adalah matriks Hessian yang merupakan turunan kedua dari fungsi $\mathbf{F}\left(\mathbf{X}_{\mathbf{n}}\right)$ dan $e_{i}$ adalah vektor berukuran $k x 1$ dengan nilai 1 jika $i=j$ dan 0 untuk $i \neq j$ serta $\otimes$ adalah kronecker product [5]. Kriteria pemberhentian iterasi metode Midpoint adalah ketika galat iterasi lebih kecil dari pada galat toleransi yang diberikan atau dapat dilihat pada Persamaan (3).

\section{METODE NMH}

Metode NMH adalah salah satu metode iterasi yang digunakan untuk menentukan nilai akar-akar persamaan dengan iterasi tiga langkah yang mengkombinasikan formula pada Persamaan (2), Persamaan (4) dan Persamaan (5). Misalkan nilai $\mathbf{X}_{\mathbf{n}+\mathbf{1}}$ pada Persamaan (2) dan Persamaan (4) masing-masing adalah $\mathbf{Z}_{\mathbf{n}}$ dan $\mathbf{Y}_{\mathbf{n}}$ sehingga diperoleh rumus metode $\mathrm{NMH}$ untuk menyelesaikan sistem persamaan nonlinier adalah sebagai berikut :

$$
\begin{gathered}
\mathbf{Z}_{\mathbf{n}}=\mathbf{X}_{\mathbf{n}}-\mathbf{J}\left(\mathbf{X}_{\mathbf{n}}\right)^{-1} \cdot \mathbf{F}\left(\mathbf{X}_{\mathbf{n}}\right), n=\mathbb{Z}^{+} \\
\mathbf{Y}_{\mathbf{n}}=\mathbf{X}_{\mathbf{n}}-\left(\mathbf{J}\left(\mathbf{X}_{\mathbf{n}}\right)+\mathbf{J}\left(\mathbf{Z}_{\mathbf{n}}\right)\right)^{-1} \cdot 2 \mathbf{F}\left(\mathbf{X}_{\mathbf{n}}\right), n=\mathbb{Z}^{+} \\
\mathbf{X}_{\mathbf{n}+\mathbf{1}}=\mathbf{Y}_{\mathbf{n}}-\left(\mathbf{J}\left(\mathbf{Y}_{\mathbf{n}}\right)-\frac{1}{2 !} \sum_{i=1}^{2} e_{i} \otimes \mathbf{J}\left(\mathbf{Y}_{\mathbf{n}}\right)^{-1} \cdot \mathbf{F}\left(\mathbf{Y}_{\mathbf{n}}\right)^{T} \cdot \mathbf{H}_{\mathbf{i}}\left(\mathbf{Y}_{\mathbf{n}}\right)\right)^{-1} \cdot \mathbf{F}\left(\mathbf{Y}_{\mathbf{n}}\right), n=\mathbb{Z}^{+} .
\end{gathered}
$$

Adapun algoritma metode NMH sebagai berikut :

1. Definisikan sistem persamaan nonlinier dua variabel $\mathbf{F}(\mathbf{X})$.

2. Tentukan galat toleransi $E_{\delta}=10^{-15}$ nilai awal $\mathbf{X}_{\mathbf{n}}$ dengan $n=\mathbb{Z}^{+}$.

3. Tentukan nilai $\mathbf{F}\left(\mathbf{X}_{\mathbf{n}}\right)$ dan $\mathbf{J}\left(\mathbf{X}_{\mathbf{n}}\right)$.

4. Hitung nilai $\mathbf{Z}_{\mathbf{n}}$ dengan metode Newton :

$\mathbf{Z}_{\mathbf{n}}=\mathbf{X}_{n}-\mathbf{J}\left(\mathbf{X}_{n}\right)^{-1} \cdot \mathbf{F}\left(\mathbf{X}_{n}\right)$

Hitung nilai $\mathbf{Y}_{\mathbf{n}}$ dengan metode Midpoint :

$\mathbf{Y}_{\mathbf{n}}=\mathbf{X}_{n}-\left(\mathbf{J}\left(\mathbf{X}_{n}\right)+\mathbf{J}\left(\mathbf{Z}_{\mathbf{n}}\right)\right)^{-1} \cdot 2 \mathbf{F}\left(\mathbf{X}_{n}\right)$

Hitung nilai $\mathbf{X}_{\boldsymbol{n}+\mathbf{1}}$ dengan metode Halley :

$$
\mathbf{X}_{\mathbf{n + 1}}=\mathbf{Y}_{\mathbf{n}}-\left[\mathbf{J}\left(\mathbf{Y}_{\mathbf{n}}\right)-\frac{1}{2 !} \sum_{i=1}^{2} e_{i} \otimes\left(\mathbf{J}\left(\mathbf{Y}_{\mathbf{n}}\right)^{-1} \cdot \mathbf{F}\left(\mathbf{Y}_{\mathbf{n}}\right)\right)^{T} \cdot \mathbf{H}_{i}\left(\mathbf{Y}_{\mathbf{n}}\right)\right]^{-1} \cdot \mathbf{F}\left(\mathbf{Y}_{\mathbf{n}}\right)
$$

5. Tentukan nilai galat iterasi:

$\mathbf{E}_{\mathbf{n}+\mathbf{1}}=\left|\mathbf{X}_{\mathbf{n}+\mathbf{1}}-\mathbf{X}_{\mathbf{n}}\right|$, dan

norm dari galat iterasi:

$\left\|\mathbf{E}_{\mathbf{n}+\mathbf{1}}\right\|=\sqrt{x^{2}+y^{2}}, x$ dan $y \in \mathbf{E}_{\mathbf{n}+\mathbf{1}}$.

6. a. jika nilai $\left\|\mathbf{E}_{\mathbf{n}+\mathbf{1}}\right\| \geq E_{\delta}$, ganti $\mathbf{X}_{\mathbf{n}}$ dengan $\mathbf{X}_{\mathbf{n}+\mathbf{1}}$ dan ulangi langkah 3 .

b. jika $\left\|\mathbf{E}_{\mathbf{n}+\mathbf{1}}\right\|<E_{\delta}$ maka iterasi berhenti.

\section{SIMULASI NUMERIK}

Pada simulasi numerik ini, metode NMH akan diterapkan pada beberapa sistem persamaan nonlinier dua variabel yang memuat fungsi polynomial, eksponensial, trigonometri dan logaritma natural. Solusi numerik yang diperoleh dari iterasi metode NMH adan dibandingkan dengan solusi 
eksaknya untuk mengetahui nilai galat yang diperoleh. Adapun sistem persamaan yang diberikan adalah sebagai berikut :

1. Diberikan suatu sistem persamaan nonlinier dua variabel yang memuat fungsi polinomial $\mathbf{F}_{\mathbf{1}}(\mathbf{X})=\left\{\begin{array}{l}f(x, y)=x^{2}-10 x+y^{2}+8=0 \\ g(x, y)=x y^{2}+x-10 y+8=0\end{array}\right.$, dengan nilai tebakan awal $\left(x_{0}, y_{0}\right)=(2,2)$ dan $E_{\delta}=10^{-15}$ akan ditentukan solusi numeriknya.

\section{Penyelesaian:}

Dengan menggunakan algoritma metode NMH, Tabel 1 adalah solusi numerik iterasi pertama dan seterusnya dari $\mathbf{F}_{\mathbf{1}}(\mathbf{X})$.

Tabel 1. Hasil Iterasi $\mathbf{F}_{\mathbf{1}}(\mathbf{X})$

\begin{tabular}{cccc}
\hline \multirow{2}{*}{ Iterasi ke- $n+1$} & \multicolumn{2}{c}{$\mathbf{E}_{\mathbf{n}+\mathbf{1}}$} & \multirow{2}{*}{$\boldsymbol{\|} \mathbf{E}_{\mathbf{n}+\mathbf{1}} \|$} \\
\cline { 2 - 3 } & 2.039633380979440 & 2.763318967301210 & 0.764347205613817 \\
2 & 2.193439219774380 & 3.020466145683250 & 0.299634623161708 \\
3 & 2.193439415415310 & 3.020466468123034 & 0.000000377150879 \\
4 & 2.193439415415310 & 3.020466468123034 & 0.000000000000000 \\
\hline
\end{tabular}

Solusi eksak riil dari sistem persamaan nonlinier $\mathbf{F}_{\mathbf{1}}(\mathbf{X})$ adalah $(x, y)=(1,1)$ dan $(x, y)=$ (2.1934394154153081387514076869577, 3.0204664681230335884184372512906). Tabel 1 menunjukkan bahwa sistem $\mathbf{F}_{\mathbf{1}}(\mathbf{X})$ dengan tebakan awal $\left(x_{0}, y_{0}\right)=(2,2)$ menggunakan metode $\mathrm{NMH}$ dapat diselesaikan sebanyak 4 kali iterasi dengan hasil numerik yang diperoleh adalah $x=$ 2.193439415415310 dan $y=3.020466468123034$. Galat yang diperoleh dari selisih antara solusi eksak dan solusi numerik adalah $(x, y)=\left(8.138751407686957 \times 10^{-15}, 3.5884184372512906 \times\right.$ $\left.10^{-15}\right)$.

2. Diberikan sebuah sistem persamaan nonlinier dua variabel yang memuat fungsi eksponensial $\mathbf{F}_{2}(\mathbf{X})=\left\{\begin{array}{c}f(x, y)=x^{4} y-x y+2 x-y-1=0 \\ g(x, y)=y e^{-x}+x-y-e^{-1}=0\end{array}\right.$, dengan nilai awal $\left(x_{0}, y_{0}\right)=(0.1,0.1)$ dan $E_{\delta}=10^{-15}$ akan ditentukan solusi numeriknya.

\section{Penyelesaian:}

Penyelesaian menggunakan algoritma metode NMH diperoleh hasil iterasi pertama dan seterusnya dari $\mathbf{F}_{2}(\mathbf{X})$ sebagai berikut:

Tabel 2. Hasil Iterasi $\mathbf{F}_{\mathbf{2}}(\mathbf{X})$

\begin{tabular}{|c|c|c|c|}
\hline \multirow{2}{*}{ Iterasi ke- $n+1$} & \multicolumn{2}{|c|}{$E_{n+1}$} & \multirow{2}{*}{$\left\|\mathbf{E}_{n+1}\right\|$} \\
\hline & $x$ & $y$ & \\
\hline 1 & 0.284339919956938 & -0.337548131310277 & 0.474794243123109 \\
\hline 2 & 0.284339920205951 & -0.337548157778744 & 0.000000026469638 \\
\hline 3 & 0.284339920205951 & -0.337548157778744 & 0.000000000000000 \\
\hline
\end{tabular}

Tabel 2 menunjukkan bahwa solusi dari $\mathbf{F}_{\mathbf{2}}(\mathbf{X})$ dengan metode NMH sebanyak 3 iterasi karena galat iterasi sudah lebih kecil daripada galat toleransi yang diberikan. Solusi numerik dengan menggunakan nilai awal $\left(x_{0}, y_{0}\right)=(0.1,0.1)$ adalah $x=0.284339920205951$ dan $y=-0.337548157778744$. Diketahui bahwa nilai eksak dari $\mathbf{F}_{\mathbf{2}}(\mathbf{X})$ adalah $x=0.28433992020595074166598071976109$ dan $y=-0.33754815777874374631886728586349$ maka galat yang diperoleh dari selisih nilai eksak dan numerik adalah $(x, y)=\left(7.4166598071976109 \times 10^{-15}, 7.4631886728586349 \times 10^{-15}\right)$.

3. Diberikan sebuah sistem persamaan nonlinier dua variabel yang memuat fungsi trigonometri $\mathbf{F}_{3}(\mathbf{X})=\left\{\begin{array}{l}f(x, y)=297.5 \cos (x)+489 \sin (y)-740.78=0 \\ g(x, y)=297.5 \sin (x)-489 \cos (y)+197=0\end{array}\right.$, dengan tebakan awal $\left(x_{0}, y_{0}\right)=$ $(0.5,0.5)$ dan $E_{\delta}=10^{-15}$ akan ditentukan solusi numeriknya. 


\section{Penyelesaian:}

Penyelesaian menggunakan algoritma metode $\mathrm{NMH}$ diperoleh solusi numerik iterasi pertama dan seterusnya dari $\mathbf{F}_{\mathbf{3}}(\mathbf{X})$ pada Tabel 3.

Tabel 3. Hasil Iterasi $\mathbf{F}_{3}(\mathbf{X})$

\begin{tabular}{|c|c|c|c|}
\hline \multirow{2}{*}{ Iterasi ke- $n+1$} & \multicolumn{2}{|c|}{$E_{n+1}$} & \multirow{2}{*}{$\left\|E_{n+1}\right\|$} \\
\hline & $x$ & $y$ & \\
\hline 1 & 0.032293177832222 & 1.134699993264050 & 0.788412171996136 \\
\hline 2 & 0.030770500758327 & 1.135608943661822 & 0.001773340434596 \\
\hline 3 & 0.030770500758327 & 1.135608943661822 & 0.000000000000000 \\
\hline
\end{tabular}

Tabel 3 menunjukkan bahwa akar dari sistem $\mathbf{F}_{3}(\mathbf{X})$ dengan metode NMH diperoleh dari 3 kali iterasi. Solusi numerik yang diperoleh dengan mengambil nilai awal $\left(x_{0}, y_{0}\right)=(0.5,0.5)$ adalah $x=$ 0.030770500758327 dan $y=1.135608943661822$. Diketahui solusi eksak dari $\mathbf{F}_{3}(\mathbf{X})$ adalah $x=0.030770500758327955535681743283777$

dan $y=1.1356089436618227709005164864045$ sehingga nilai galat yang diperoleh dari selisih solusi numerik dan solusi eksak adalah $(x, y)=\left(9.55535681743283777 \times 10^{-15}, 7.709005164864045 \times 10^{-15}\right)$.

4. Diberikan sebuah sistem persamaan nonlinier dua variabel yang memuat fungsi logaritma natural $\mathbf{F}_{\mathbf{4}}(\mathbf{X})=\left\{\begin{array}{l}f(x, y)=x^{2}+3 x+\ln (2 x+1)-y=0 \\ g(x, y)=y^{2}+3 y+\ln (2 y+1)-x=0\end{array}\right.$, dengan tebakan awal $\left(x_{0}, y_{0}\right)=(0.1,0.1)$ dan $E_{\delta}=10^{-15}$ akan ditentukan solusi numeriknya.

\section{Penyelesaian:}

Penyelesaian menggunakan algoritma metode $\mathrm{NMH}$ diperoleh solusi numerik iterasi pertama dan seterusnya dari $\mathbf{F}_{\mathbf{4}}(\mathbf{X})$ sebagai berikut :

Tabel 4. Hasil Iterasi $\mathbf{F}_{\mathbf{4}}(\mathbf{X})$

\begin{tabular}{cccc}
\hline \multirow{2}{*}{ Iterasi ke- $n+1$} & \multicolumn{2}{c}{$\mathbf{E}_{\mathbf{n}+\mathbf{1}}$} & \multirow{2}{*}{$\left\|\mathbf{E}_{\mathbf{n}+\mathbf{1}}\right\|$} \\
\cline { 2 - 3 } & 0.011200760214310 & 0.011200760214310 & 0.125581089233344 \\
2 & 0.001245581051216 & 0.001245581051216 & 0.014078749388301 \\
3 & 0.000138410692670 & 0.000138410692670 & 0.001565775336913 \\
4 & 0.000015379123567 & 0.000015379123567 & 0.000173992913625 \\
5 & 0.000001708793454 & 0.000001708793454 & 0.000019332766248 \\
6 & 0.000000189865963 & 0.000000189865963 & 0.000002148087858 \\
7 & 0.000000021096218 & 0.000000021096218 & 0.000000238676462 \\
8 & 0.000000002344024 & 0.000000002344024 & 0.000000026519607 \\
9 & 0.000000000260447 & 0.000000000260447 & 0.000000002946623 \\
10 & 0.000000000028939 & 0.000000000028939 & 0.000000000327403 \\
11 & 0.000000000003215 & 0.000000000003215 & 0.000000000036378 \\
12 & 0.000000000000357 & 0.000000000000357 & 0.000000000004042 \\
13 & 0.000000000000040 & 0.000000000000040 & 0.000000000000449 \\
14 & 0.000000000000004 & 0.000000000000004 & 0.000000000000050 \\
15 & 0.000000000000000 & 0.000000000000000 & 0.000000000000006 \\
16 & 0.000000000000000 & 0.000000000000000 & 0.000000000000000 \\
\hline
\end{tabular}

Tabel 4 menunjukkan bahwa hasil iterasi $\mathbf{F}_{\mathbf{4}}(\mathbf{X})$ dengan metode NMH sebanyak 16 kali. Solusi akhir yang diperoleh dengan mengambil tebakan awal $\left(x_{0}, y_{0}\right)=(0.1,0.1)$ adalah $x=0$ dan $y=0$. 
Diketahui bahwa solusi eksak dari $\mathbf{F}_{\mathbf{4}}(\mathbf{X})$ adalah $x=0$ dan $y=0$ sehingga galat yang diperoleh dari selisih solusi numerik dan solusi eksak adalah $(x, y)=(0,0)$.

\section{KESIMPULAN}

Berdasarkan pembahasan yang telah dipaparkan, maka diperoleh kesimpulan yaitu:

1. Metode NMH dapat menyelesaikan sistem persamaan nonlinier rumus berikut:

$$
\begin{gathered}
\mathbf{Z}_{\mathbf{n}}=\mathbf{X}_{\mathbf{n}}-\mathbf{J}\left(\mathbf{X}_{\mathbf{n}}\right)^{-1} \cdot \mathbf{F}\left(\mathbf{X}_{\mathbf{n}}\right) \\
\mathbf{Y}_{\mathbf{n}}=\mathbf{X}_{\mathbf{n}}-\left(\mathbf{J}\left(\mathbf{X}_{\mathbf{n}}\right)+\mathbf{J}\left(\mathbf{Z}_{\mathbf{n}}\right)\right)^{-1} \cdot 2 \mathbf{F}\left(\mathbf{X}_{\mathbf{n}}\right) . \\
\mathbf{X}_{\mathbf{n}+\mathbf{1}}=\mathbf{Y}_{\mathbf{n}}-\left(\mathbf{J}\left(\mathbf{Y}_{\mathbf{n}}\right)-\frac{1}{2 !} \sum_{i=1}^{2} e_{i} \otimes \mathbf{J}\left(\mathbf{Y}_{\mathbf{n}}\right)^{-1} \cdot \mathbf{F}\left(\mathbf{Y}_{\mathbf{n}}\right)^{T} \cdot \mathbf{H}_{\mathbf{i}}\left(\mathbf{Y}_{\mathbf{n}}\right)\right)^{-1} \cdot \mathbf{F}\left(\mathbf{Y}_{\mathbf{n}}\right) .
\end{gathered}
$$

2. Dari simulasi yang diberikan, metode $\mathrm{NMH}$ dapat menyelesaikan masing-masing sistem persamaan nonlinier dengan galat toleransi iterasi yang diberikan $E_{\delta}=10^{-15}$ sebagai berikut:

i. $\quad \mathbf{F}_{\mathbf{1}}(\mathbf{X})=\left\{\begin{array}{l}f(x, y)=x^{2}-10 x+y^{2}+8=0 \\ g(x, y)=x y^{2}+x-10 y+8=0\end{array}\right.$ dengan tebakan awal $(x, y)=(2,2)$ diperoleh solusi numeriknya adalah $(x, y)=(2.193439415415310,3.020466468123034)$ dan selisih antara solusi numerik dan solusi eksaknya adalah $(x, y)=(8.138751407686957 \times$ $\left.10^{-15}, 3.5884184372512906 \times 10^{-15}\right)$.

ii. $\mathbf{F}_{2}(\mathbf{X})=\left\{\begin{array}{c}f(x, y)=x^{4} y-x y+2 x-y-1=0 \\ g(x, y)=y e^{-x}+x-y-e^{-1}=0\end{array}\right.$ dengan tebakan awal $\left(x_{0}, y_{0}\right)=(0.1,0.1)$ diperoleh solusi numeriknya adalah $(x, y)=(0.284339920205951,-0.337548157778744)$ dan galat sebesar $(x, y)=\left(7.4166598071976109 \times 10^{-15}, 7.4631886728586349 \times 10^{-15}\right)$ iii. $\mathbf{F}_{\mathbf{3}}(\mathbf{X})=\left\{\begin{array}{l}f(x, y)=297.5 \cos (x)+489 \sin (y)-740.78=0 \\ g(x, y)=297.5 \sin (x)-489 \cos (y)+197=0\end{array}\right.$ dengan tebakan awal $\left(x_{0}, y_{0}\right)=$ $(0.5,0.5)$ diperoleh solusi numerik dari sistem adalah $(x, y)=(0.030770500758329$, $1.135608943661820)$ dan galat sebesar $(x, y)=\left(9.55535681743283777 \times 10^{-15}\right.$, $\left.7.709005164864045 \times 10^{-15}\right)$.

iv. $\mathbf{F}_{\mathbf{4}}(\mathbf{X})=\left\{\begin{array}{l}f(x, y)=x^{2}+3 x+\ln (2 x+1)-y=0 \\ g(x, y)=y^{2}+3 y+\ln (2 y+1)-x=0\end{array}\right.$ dengan tebakan awal $\left(x_{0}, y_{0}\right)=(0.1,0.1)$ diperoleh solusi numeriknya adalah $(x, y)=(0,0)$ dan galat sebesar $(x, y)=(0,0)$.

\section{DAFTAR PUSTAKA}

[1] Anton, H., dan Rorres, C., 2013, Elementary Linear Algebra, Ed ke-11, John Wiley and Sons, Hoboken.

[2] Munir, R., 2015, Metode Numerik, Informatika, Bandung.

[3] Ozban AY., 2004, Some new variants of Newton's methods, Applied Mathematic Letters, 17:677682.

[4] Pramatasyari D.A., 2017, Kombinasi varian metode Newton dan metode Halley untuk menyelesaikan persamaan nonlinier, Institut Pertanian Bogor, Thesis.

[5] Hafiz, MA., dan Baghdad, SM., 2012, Extended And Modified Halley's Iterative Method For Solving Nonlinear Systems, J. Math. Comput. Sci. No. 5, 1512-1521.

FITRI NUR HIDAYAH : Jurusan Matematika FMIPA Untan, Pontianak, fitrinurhidayah@student.untan.ac.id

YUNDARI

: Jurusan Matematika FMIPA Untan, Pontianak, yundari@math.untan.ac.id

MARIATUL KIFTIAH : : Jurusan Matematika FMIPA Untan, Pontianak, kiftiahmariatul@math.untan.ac.id 